\title{
Proxy-reported questionnaires for young children with asthma: a structured review
}

\author{
Amy Barrett ${ }^{1}$, Marci Clark², Carla DeMuro² and Dirk Esser ${ }^{3}$ \\ Affiliations: \\ ${ }^{1} \mathrm{RTI}$ Health Solutions, Manchester, UK. \\ ${ }^{2} \mathrm{RTI}$ Health Solutions, Research Triangle Park, NC, USA. \\ ${ }^{3}$ Boehringer Ingelheim $\mathrm{GmbH}$, Ingelheim, Germany.
}

Correspondence: A. Barrett, RTI Health Solutions, 2nd Floor, The Pavilion, Towers Business Park, Wilmslow Road, Didsbury, Manchester, M20 2LS, UK.

E-mail: abarrett@rti.org

ABSTRACT Which proxy-reported outcome measures have been developed for use with children aged 6 years and younger to assess asthma symptoms, asthma control, and asthma-specific health-related quality of life, and do these questionnaires' measurement properties support their use as end-points in clinical trials?

A two-phase literature search was conducted: 1) studies describing relevant questionnaires were identified, and the questionnaires were assessed against predefined criteria; 2) studies providing information on the measurement properties of questionnaires meeting the predefined inclusion criteria were identified. Literature sources included PubMed and EMBASE databases, scientific conference proceedings, a clinical trial registry, and a quality of life instrument database.

The initial search of literature databases and conference abstracts identified 631 records. 20 paediatric asthma proxy-reported outcome instruments were identified; seven met the inclusion criteria: Childhood Asthma Control Test, Control de Asma en Niños Questionnaire, Pediatric Asthma Caregiver Diary, Pediatric Asthma Control Tool, PedsQL 3.0 Short-Form 22 Asthma Module, PedsQL Asthma Symptoms Scale, and Test for Respiratory and Asthma Control in Kids.

Three proxy-reported outcome instruments were considered suitable for use as end-points in paediatric asthma clinical trials; the Pediatric Asthma Caregiver Diary possesses the strongest measurement properties of the three.

@ERSpublications

Among 3 potentially useful proxy-reported measures for paediatric asthma trials, the PACD daily diary is recommended http://ow.ly/lmh9x 


\section{Introduction}

Asthma is the most common chronic health condition among children [1, 2]. An estimated 7 million children aged 17 years or younger in the USA have documented asthma [3], and 1.5 million children aged 2 to 15 years in the UK report asthma symptoms [4]. Asthma in children results in significant morbidity and mortality [5], accounting annually for one-third of all hospitalisations related to asthma [6]. Children with asthma experience a higher burden of illness [7] and lower health-related quality of life (HRQOL) [8-10] than those without a chronic health condition. A key goal of asthma intervention includes achieving and maintaining asthma control [11], thereby reducing the burden of illness and improving the HRQOL of children with persistent asthma [10].

Collecting patient-reported outcomes (PROs) from paediatric patients presents unique challenges, including identifying the age or developmental stage at which children can reliably and reproducibly report their health status. Although children as young as 5 years reportedly have provided empirically reliable assessments of concrete concepts, such as pain or medication use, research supports a more conservative estimate of 9 or 10 years as the age at which children can reliably report on subjective concepts such as behaviour [12]. JUNIPER [13] reported that girls as young as 7 years provided reliable responses when they completed the self-reported version of the Paediatric Asthma Quality of Life Questionnaire (PAQLQ), but boys' responses were not considered reliable until the age of 10 to 11 years, because the boys in the study frequently exhibited a lack of concentration, despite having sufficient literacy and numeracy skills to complete the questionnaire.

Children's ability to make discriminations like those required in assessments of asthma symptoms, asthma control, and HRQOL also has been called into question. ANNETT et al. [14] administered a comprehensive battery of child-reported psychosocial health status, asthma severity, and disease-specific HRQOL instruments to 339 children with asthma (ages 5-12 years) during a 12-month follow-up of a randomised study. They concluded that child-reported instruments principally measure the child's subjective discomfort with his or her asthma at the time of evaluation, and may not necessarily correspond with clinical episodes of asthma symptoms or other components of functional status [14].

In general, caregiver (i.e. proxy) perception of HRQOL and symptom level is a primary determinant of healthcare utilisation in young children [15-17]. Use of proxy reporting of symptoms and rescue medication in determining asthma control in young children is also supported by expert opinion [11]. Because very young children are unable to accurately perform some physiological tests (e.g. lung function testing and bronchial challenge) $[11,18]$ and because normative values for the tests are not available for this population [19-23], clinicians frequently rely on patterns of hallmark symptoms (e.g. wheeze, cough and breathlessness, which typically result in activity limitation) reported by the child's caregiver [11]. Proxy reporting of observable symptoms for patients who cannot respond for themselves is supported by the US Food and Drug Administration (FDA)'s PRO guidance [24].

Studies comparing self-reported and caregiver proxy-reported assessments in healthy as well as chronically ill children have shown higher levels of agreement in assessment of symptoms than in assessment of subjective psychosocial concepts [8, 25-27]. These findings support the use of proxy-reported outcomes (PxROs) in assessing asthma symptoms and asthma control in young children with asthma [18, 28]. However, PxROs, preferably well-developed objective measures, should be selected carefully on the basis of a thorough assessment of their psychometric properties. Both the FDA [24] and the European Medicines Agency $[29,30]$ have established standards for the development and validation of PRO measures and, to a lesser extent, PxRO measures used in clinical trials as the basis of promotional claims. This review has been conducted to identify and evaluate asthma PxRO measures best meeting these standards.

Two self-report instruments frequently used in clinical trials of asthma treatment have been validated for use in children: the interviewer-administered PAQLQ assesses paediatric asthma-related quality of life and is valid for use in children as young as 7 years [13]; the interviewer-administered Asthma Control Questionnaire assesses asthma control and is valid for use in children aged 6 years and older [31]. Although, as previously discussed, no universally agreed-upon minimum age exists for reliable self-reporting among children, a minimum age of 7 years has been recommended by the Critical Path Institute [32]. We therefore focused this review on PxRO measures for use in patients aged 6 years and younger.

The specific objectives of this review were three-fold: 1) to identify available asthma-specific PxRO measures for young children (aged 6 years and younger) including HRQOL questionnaires, asthma symptom diaries, and asthma control questionnaires; 2) to describe the psychometric properties and responsiveness of the identified instruments; and 3) to evaluate their usefulness in assessing aspects of paediatric asthma treatment benefit in the context of a clinical trial. 


\section{Methods}

Search strategy

The goal of the initial searches was to identify PxRO instruments used to assess young children with asthma. The following sources were searched: 1) PubMed (including MEDLINE) and EMBASE literature databases; 2) conference proceedings from the American Thoracic Society (ATS) and European Respiratory Society (ERS); 3) a clinical trial registry (ClinicalTrials.gov) [33]; and 4) Patient-Reported Outcome and Quality of Life Instruments Database (PROQOLID) [34].

During the first phase of the literature review, PubMed and EMBASE searches were limited to studies published in English between January 2001 and April 2011; search terms were combinations of keywords and indexing terms related to asthma, children or paediatric populations, and PxROs (e.g. parent, caregiver, questionnaire and diary). Searches of the ATS and ERS 2009 and 2010 conference meeting abstracts and ClinicalTrials.gov used combinations of the terms asthma, child or paediatric/pediatric, and questionnaire, diary or instrument. We reviewed the publically available portion of the PROQOLID Web site for instruments classified as being developed for paediatric asthma populations. Using pre-specified instrument inclusion criteria (described in the following section), we selected studies related to instruments of potential interest as end-points in interventional clinical trials in paediatric asthma.

During the second phase of the review, names and acronyms of instruments meeting the inclusion criteria were used as terms for targeted searches of PubMed and EMBASE, with no limitations on publication date. These searches were conducted to gather additional information on the development process and measurement properties of specific instruments or their use in clinical or observational studies.

\section{Inclusion and exclusion criteria}

Inclusion criteria were developed to satisfy the objectives of the literature review. Included studies described the development, validation, evaluation, or use of an instrument of interest, defined as an instrument developed for caregiver or parent (proxy) report of asthma-specific HRQOL, asthma symptoms, or asthma control in children aged 6 years or younger. Instruments that assess primarily family functioning; caregiver HRQOL; or communication, behaviour or attitudes related to asthma were excluded. Asthma screening instruments or instruments that assess only one asthma symptom (e.g. wheeze) or assess utilities related to asthma treatment for economic purposes were also excluded. Instruments with no evidence of caregiver involvement in the development process (during item generation or modification, evaluation of item completeness or acceptability, or item reduction) were excluded unless they had a significant history of use in assessing asthma treatment benefit in clinical trials.

\section{Data extraction and interpretation}

Information extracted from the studies included the instrument's objective (e.g. clinical practice or interventional studies), development process, content, and key measurement properties.

Reliability is concerned with whether an instrument is internally consistent or reproducible. Internal consistency is the extent to which items comprising a scale measure the same concept. Test-retest reliability takes account of variation over time and is usually determined with stable patients. The results of tests of internal consistency and test-retest reliability, specifically Cronbach's $\alpha$ coefficients [35] and test-retest intraclass correlation coefficients (ICCs), were extracted.

Validity generally refers to whether an instrument measures what it intends to measure. This review assessed several types of validity. Evidence of face validity and content validity were sought in the details of the development process for the instruments, specifically whether there was input from the relevant patient population [36] and individuals with relevant clinical or health status methodology expertise [37]. As per the FDA PRO Guidance, the target patient population should provide input in the development of item concepts and item wording, evaluate the completeness of item coverage, and assess the items' clarity and readability [24].

We also examined two types of construct validity, convergent and divergent validity. Establishment of convergent and divergent validity is built through comparisons in multiple studies, and the studies ideally should include a priori hypotheses that the instrument being tested will have patterns of stronger correlations with some variables (convergent validity) and patterns of weaker correlations with others (divergent validity). Validity also can be evaluated quantitatively through factor analysis, the statistical analysis of patterns of items that may assess single underlying distinct constructs or dimensions [38]. Information relating to the use of these techniques is presented. 
We noted evidence of each instrument's discriminant validity, or known-groups validity, which refers to an instrument's ability to discriminate between groups of patients with different health status, disease severity level, or outcome.

Responsiveness refers to the ability of an instrument to measure important changes in health, which, in a clinical trial, might reflect therapeutic effects $[39,40]$. Responsiveness is assessed by looking at changes in instrument scores for groups of patients whose health is known to have changed over time. Evidence of responsiveness in a clinical trial of asthma treatment or longitudinal results described in development articles were extracted, as available, to provide evidence of instrument responsiveness.

Recommendations for PxRO measures were based on an overall consideration of each instrument's strengths, weaknesses and fitness for purpose for use as an end-point in clinical trials.

\section{Results}

\section{Search results}

The initial searches of PubMed, EMBASE, and the ATS and ERS conferences identified 631 records. Figure 1 summarises the inclusion or exclusion decisions along with the reasons for exclusion for these records.

The 27 included studies described 15 potentially relevant paediatric asthma PxRO instruments. Reviews of the PROQOLID database and ClinicalTrials.gov identified five additional instruments. A total of 20 paediatric asthma PxRO instruments were identified and seven met the pre-specified instrument inclusion criteria: Childhood Asthma Control Test (C-ACT) [41], Control de Asma en Niños (CAN) (Asthma Control in Children) [42], Pediatric Asthma Caregiver Diary (PACD) [18, 43], Pediatric Asthma Control Tool (PACT) [44], Pediatric Quality of Life Inventory (PedsQL) 3.0 Asthma Module Asthma Symptoms Scale (PedsQL Asthma Symptoms Scale) [45], PedsQL 3.0 SF22 Asthma Module (a short form of the

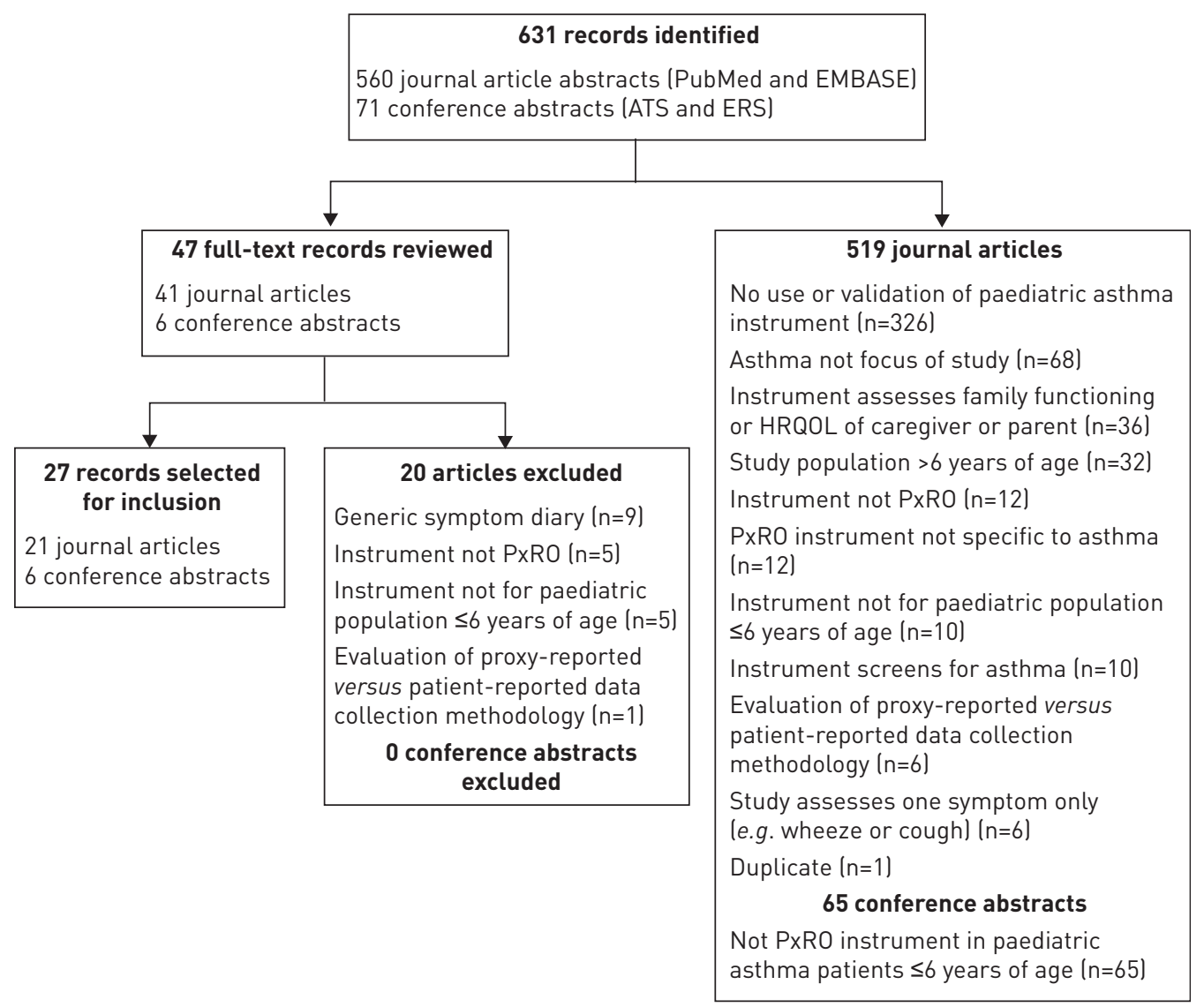

FIGURE 1 Reference source flow chart for initial instrument review. ATS: American Thoracic Society annual conference, 2009 and 2010; ERS: European Respiratory Society annual conference, 2009 and 2010; HRQOL: health-related quality of life; PxRO: proxy-reported outcome. 


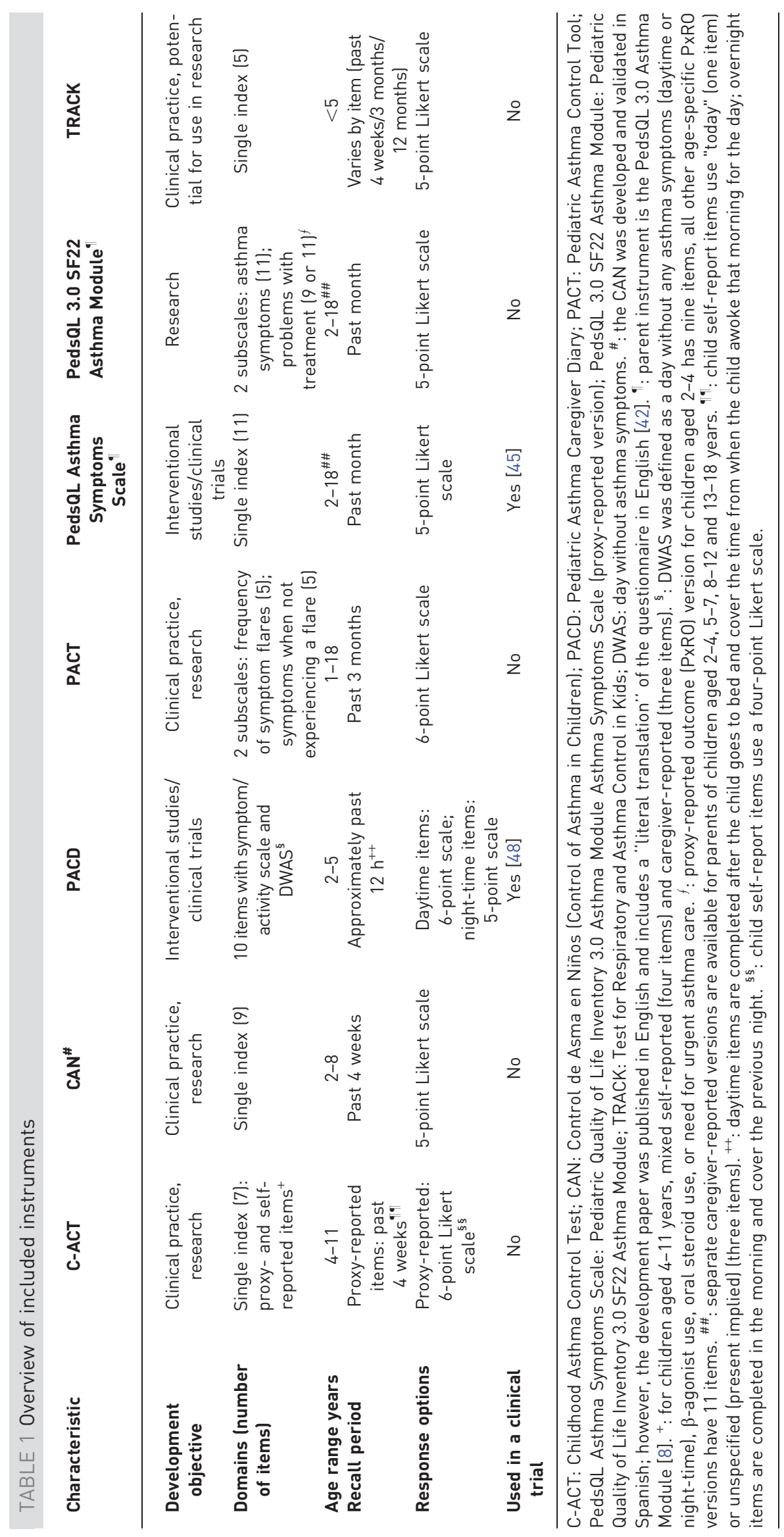


PedsQL 3.0 Asthma Module) [46], and Test for Respiratory and Asthma Control in Kids (TRACK) [47]. 13 instruments did not meet the pre-specified instrument inclusion criteria and were excluded.

A further targeted search was conducted to gather additional development and validation information on the seven included instruments; this search identified a total of 132 PubMed and EMBASE records, eight of which provided relevant information and were included. Combining the results of the initial and targeted searches, a total of 35 articles and conference presentations were selected for inclusion.

\section{Comparison of included instruments}

Table 1 provides a brief overview of the seven included instruments. Four instruments are single indexes with no subscales (C-ACT, CAN, TRACK, PedsQL Asthma Symptoms Scale), and two instruments have two subscales (PACT, PedsQL 3.0 SF22 Asthma Module). The PACD was the only daily diary identified. It has 10 items from which one scale and a day without asthma symptoms (DWAS) were defined.

The concepts most commonly evaluated by the included measures were: interference of symptoms with activity; night-time awakening; wheezing; coughing; difficulty breathing; frequency of asthma exacerbations; and need for rescue medication (table 2). All of the measures assessed interference of asthma symptoms with activity (e.g. during play, sports or running); however, in the C-ACT this concept was assessed with a patient-reported rather than a proxy-reported item. Although asthma symptoms were evaluated by each instrument in some form, assessment varied by type (e.g. general assessment of daytime symptoms overall versus individual assessment of specific daytime symptoms such as cough or wheeze). The PACD, PACT and TRACK assessed the need for rescue medication. Although the CAN, PACD, PACT and TRACK assessed healthcare resource utilisation in some way, the PACT was most comprehensive in this area. Exacerbation frequency was assessed by the PACT, PedsQL 3.0 SF22 Asthma Module and PedsQL Asthma Symptoms

TABLE 2 Comparison of proxy-reported concepts covered by instruments of interest

$\begin{array}{lcccccc}\text { Proxy-reported concept } & \text { C-ACT } & \text { CAN }^{*} & \text { PACD }^{\#} & \text { PACT } & \begin{array}{c}\text { PedsQL } 3.0 \text { SF22 } \\ \text { Asthma Module }\end{array} & \begin{array}{c}\text { PedsQL Asthma } \\ \text { Symptoms Scale }\end{array}\end{array}$

\begin{tabular}{|c|c|c|c|}
\hline \multicolumn{3}{|l|}{ General symptoms } & Breathing problems \\
\hline \multicolumn{4}{|l|}{ Night-time symptoms } \\
\hline \multicolumn{4}{|l|}{ Specific symptoms } \\
\hline Night-time awakening & $x$ & & \\
\hline Cough & & $\mathrm{DT} / \mathrm{NT}$ & $\mathrm{DT} / \mathrm{NT}$ \\
\hline Wheeze & $x$ & $\mathrm{DT} / \mathrm{NT}$ & DT \\
\hline Trouble/difficulty breathing & & $\mathrm{DT} / \mathrm{NT}$ & DT \\
\hline \multicolumn{4}{|l|}{ Chest pain/tightness } \\
\hline \multicolumn{4}{|l|}{ Runny/stuffy nose } \\
\hline \multicolumn{4}{|l|}{ List of symptoms to select } \\
\hline \multicolumn{4}{|l|}{ Functional interference } \\
\hline Interference during activity & & $x$ & DT \\
\hline \multicolumn{4}{|l|}{ Medication use or HCRU } \\
\hline Rescue medication/ $\beta$-agonist use & & & $\mathrm{DT} / \mathrm{NT}$ \\
\hline Visit HCP or take oral prednisone & & & DT \\
\hline \multicolumn{4}{|l|}{ Start/take oral corticosteroid } \\
\hline Emergency department visit & & $\times$ & \\
\hline Hospitalisation & & $\times$ & \\
\hline \multicolumn{4}{|l|}{ Exacerbation episodes } \\
\hline \multicolumn{4}{|l|}{ Frequency of episodes } \\
\hline \multicolumn{4}{|l|}{ Frequency of episodes $\geqslant 1$ week } \\
\hline \multicolumn{4}{|l|}{ Anxiety/worry } \\
\hline Scared during exacerbation & & & \\
\hline Treatment problems & & & \\
\hline
\end{tabular}

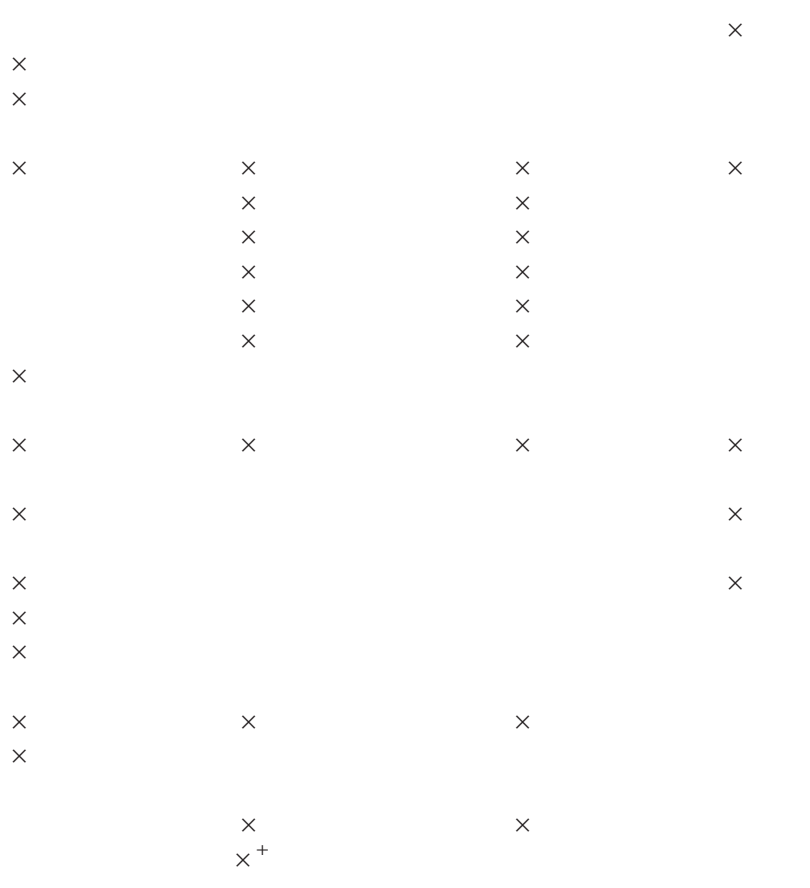

C-ACT: Childhood Asthma Control Test; CAN: Control de Asma en Niños (Control of Asthma in Children); PACD: Pediatric Asthma Caregiver Diary; PACT: Pediatric Asthma Control Tool; PedsQL 3.0 SF22 Asthma Module: Pediatric Quality of Life Inventory 3.0 SF22 Asthma Module; PedsQL Asthma Symptoms Scale: Pediatric Quality of Life Inventory 3.0 Asthma Module Asthma Symptoms Scale (proxy-reported version); TRACK: Test for Respiratory and Asthma Control in Kids; HCRU: healthcare resource utilisation; HCP: healthcare provider; DT: daytime; NT: night-time. \#: some items have daytime and night-time versions; ": e.g. cough, wheeze, shortness of breath; ${ }^{+}$: PedsQL 3.0 SF22 Asthma Module includes a domain with nine or 11 items, depending on the age of the child, assessing treatment problems. 
Scale. The PedsQL 3.0 SF22 Asthma Module and PedsQL Asthma Symptoms Scale both assessed anxiety or worry during an exacerbation, but only the PedsQL 3.0 SF22 Asthma Module assessed treatment problems. Some concepts (e.g. visiting a healthcare provider or taking oral prednisone, getting scared during an exacerbation) were included in only one measure.

Because of the nature of PxROs, most of the questionnaires focus on observable symptoms or effects of asthma, rather than concepts related to a patient's experience of asthma, such as bother caused by the condition, anxiety or HRQOL, which would require subjective assessment by a caregiver on behalf of the patient.

\section{Reliability}

Evidence of instrument reliability (internal consistency and test-retest reliability) as published in the identified literature is presented in table 3. All of the included instruments reported acceptable internal consistency, with Cronbach's $\alpha$ coefficients between 0.70 and 0.95 .

Evaluation of test-retest reliability was not reported for the CAN, PACT, PedsQL Asthma Symptoms Scale, or PedsQL 3.0 SF22 Asthma Module. The ICC was acceptable for the C-ACT and for some items of the PACD in stable patients. The TRACK did not achieve an acceptable test-retest ICC value.

The PACD was evaluated in a 3-week prospective study including 125 caregiver parents and their children [18]. Test-retest reliability for the PACD was assessed using diary data from the last 3 days of week two and the first 3 days of week three "to provide a stable period and to prevent parents from using the answers to their second week's diary when answering the third week's diary" to reduce artificial inflation of reliability estimates [18]. Test-retest reliability was acceptable for the symptom/activity scale in the stable group but not in the unstable group, as would be expected [18].

The C-ACT test-retest reliability (ICC 0.70) was reported in a conference poster, and no additional information about the population or time period of data collection was provided; however, the study design

TABLE 3 Instrument reliability evidence

\begin{tabular}{|c|c|c|}
\hline Instrument & Internal consistency (Cronbach's $\alpha)^{\#}$ & Test-retest (ICC) ${ }^{\top}$ \\
\hline C-ACT [41] & $0.79[41]$ & $0.70[49]$ \\
\hline CAN [42] & 0.825 & Not reported \\
\hline PACD [18] & $\begin{array}{l}\text { All items } 0.70-0.95 \\
\text { Daytime symptom/activity scale } 0.90\end{array}$ & $\begin{array}{l}\text { Overall } \\
\text { Stable group }{ }^{+} 0.53 \text { (wheeze) }-0.81 \text { (cough) } \\
\text { Unstable group } \$ \text { } 0.44 \text { (cough) }-0.69 \text { (trouble breathing) } \\
\text { Daytime symptom/activity scale } \\
\text { Stable group } 0.75 \\
\text { Unstable group } 0.62\end{array}$ \\
\hline РACT [44] & $\begin{array}{l}\text { Frequency of flares domain } 0.81 \\
\text { Symptoms at best domain } 0.83\end{array}$ & Not reported \\
\hline PedsQL Asthma Symptoms Scale [45] & 0.81 & Not reported \\
\hline PedsQL 3.0 SF22 Asthma Module [46] & $\begin{array}{l}\text { Asthma symptoms scale } \\
\text { Children } 2-4 \text { years } 0.91 \\
\text { Children } 5-7 \text { years } 0.90 \\
\text { Treatment problems scale } \\
\text { Children } 2-4 \text { years } 0.87 \\
\text { Children } 5-7 \text { years } 0.71\end{array}$ & Not reported \\
\hline TRACK [47] & $\begin{array}{l}\text { Development sample } 0.75[47] \\
\text { Validation sample } 0.71[47] \\
0.76 \text { at baseline }{ }^{f}[50] \\
0.74 \text { at follow-up }{ }^{f}[50]\end{array}$ & $\begin{array}{l}0.63 \text { for the subsample of children whose physician- } \\
\text { reported } \\
\text { asthma control status stayed the same at both visits [50] }\end{array}$ \\
\hline
\end{tabular}

ICC: intraclass correlation coefficient; C-ACT: Childhood Asthma Control Test; CAN: Control de Asma en Niños (Control of Asthma in Children); PACD: Pediatric Asthma Caregiver Diary; PACT: Pediatric Asthma Control Tool; PedsQL Asthma Symptoms Scale: Pediatric Quality of Life Inventory 3.0 Asthma Module Asthma Symptoms Scale (proxy-reported version); PedsQL 3.0 SF22 Asthma Module: Pediatric Quality of Life Inventory 3.0 SF22 Asthma Module; TRACK: Test for Respiratory and Asthma Control in Kids. ${ }^{\#}$ : range for acceptable Cronbach's $\alpha:>0.70$ but $\leqslant 0.95$ [35]; ${ }^{\circ}$ : threshold for acceptable test-retest reliability: ICC of $\geqslant 0.70[51]$; ${ }^{+}$: children assessed at baseline of the 3 -week study as having stable asthma symptoms requiring no change in anti-inflammatory asthma therapy (inhaled corticosteroids or cromolyn); ${ }^{\S}$ : children assessed at baseline of the 3 -week study as having unstable asthma or an asthma exacerbation requiring addition of new anti-inflammatory asthma therapy or an increase in current anti-inflammatory asthma therapy; ${ }^{f}$ : development sample $(n=321)$ only, validation sample $(n=165)$ values were similar. 
entailed administering the C-ACT to children with asthma and their caregivers at two visits, 4-6 weeks apart $(\mathrm{n}=338)[49]$.

The TRACK test-retest reliability ICC was 0.63 as assessed with a subsample of children whose physicianreported asthma control status was the same at the initial physician visit (baseline) and 4-6 weeks later at the follow-up visit.

\section{Validity}

The involvement of caregivers or parents of children with asthma in the generation or confirmation of questionnaire items was a criterion for inclusion in this review; therefore, content or face validity has been established during the development process for each of the included instruments. In addition to caregiver involvement, the use of focus groups or working groups comprised of physicians with expertise in asthma was described in the development process for the C-ACT, CAN, PACT, TRACK and the parent instrument of the PedsQL 3.0 SF22 Asthma Module and PedsQL Asthma Symptoms Scale, the PedsQL 3.0 Asthma Module.

Construct validity was supported by factor analysis for the TRACK only. In the development and validation samples, five potential factors were found to underlie the pattern of associations among the item responses. In both samples, the correlations between each item and the a priori hypothesised factor were all greater than 0.70 , supporting the conceptual model developed for respiratory control in young children [47].

For the other instruments, convergent validity was demonstrated primarily through correlation with instruments assessing similar constructs and with clinical variables, such as physician assessments of symptom intensity, asthma control, need for change in therapy or the presence of asthma exacerbations (table 4).

The development papers for the PACT, PedsQL 3.0 SF22 Asthma Module, PedsQL Asthma Symptoms Scale, and TRACK (factor analysis) presented explicit a priori hypotheses about expected strong correlations with similar constructs. The developers of the C-ACT and PACT simply stated that the relationships were examined to evaluate concurrent validity and convergent validity, respectively. None of the development papers presented a priori hypotheses related to divergent validity.

Many of the Pearson's correlation coefficients ( $r$ ) in support of convergent validity showed moderate correlations ( $\mathrm{r}$ values between 0.10 and 0.50 ). The strongest correlations were between: the C-ACT and the PAQLQ and the C-ACT and the Paediatric Asthma Caregiver's Quality of Life Questionnaire (PACQLQ); the PACD Symptom/Activity scale and the change in $\beta$-agonist treatments; the PACT and a quality of life measure and the PACT and a specialist clinician assessment; and the PedsQL Asthma Symptoms Scale and the PedsQL 4.0 Generic Core Scales. The PACD evaluated correlations between change in the PACD domains and change in the other scales, with correlations for the symptom/activity scale generally higher than those for DWAS. The values of the correlations of the CAN and the PACT with forced expiratory volume in $1 \mathrm{~s}(\mathrm{FEV} 1)$ were low, and were similar to the weaker correlations with FEV1 previously described in the literature comparing quality of life assessments in paediatric asthma patients $[52,57]$.

Table 4 also presents evidence of discriminant validity, with p-values for comparisons of patient subgroups. The instruments commonly discriminated among patients with differing asthma symptom severity levels, physician assessment of asthma control and physician recommendation of change in therapy. The ability of the C-ACT to differentiate on the basis of $\mathrm{FEV}_{1} \%$ predicted or $\mathrm{FEV} 1 /$ forced vital capacity was marginally significant and not statistically significant, respectively.

\section{Responsiveness}

In a clinical trial, advanced knowledge of instrument responsiveness facilitates the selection of appropriate measures and accurate estimation of sample size and aids in prioritising and reducing the number of outcomes to be assessed [58]. Demonstrated responsiveness of the PxRO measure in a randomised controlled trial (RCT) evaluating asthma drug therapy was a key consideration in this review, and this type of responsiveness was identified only for the PACD. The PedsQL Asthma Symptoms Scale was included as a secondary end-point in a clinical trial evaluating a behavioural intervention among caregivers of paediatric asthma patients. Longitudinal results from development studies were reported for the C-ACT, CAN, and TRACK. No published evaluation of the responsiveness of the PACT or the PedsQL 3.0 SF22 Asthma Module was identified.

The PACD identified statistically significant differences in treatment and placebo groups in an RCT of montelukast versus placebo in children aged 2 to 5 years [48]. The PACD was sensitive to: differences in the percentage of days with daytime symptoms; the percentage of DWAS; changes in overall daytime asthma symptom scores; changes in symptoms scores for cough, wheeze, trouble breathing and activity limitations; 
TABLE 4 Instrument validity evidence

\begin{tabular}{|c|c|c|}
\hline Instrument & Construct validity ${ }^{\#}$ Pearson's correlation coefficient (r) & Discriminant/known-groups validity" \\
\hline \multirow{4}{*}{ C-ACT [41] } & $P A Q L Q^{+}[52]$ domain scores, $r=0.47$ & Specialist rating of asthma control $(p<0.0001)$ \\
\hline & PACQLQ [50] domain scores, $r=0.68$ & Change in patient therapy $(p<0.0001)$ \\
\hline & & FEV $1 \%$ pred $(p=0.0494)$ \\
\hline & & $\mathrm{FEV} 1 / \mathrm{FVC}$ (NS) \\
\hline \multirow[t]{7}{*}{ CAN [42] } & FEV1 $r=-0.136(p=0.026)$ & Asthma severity $(p<0.001)$ \\
\hline & & Symptom intensity \\
\hline & & Cough $(p<0.001)$ \\
\hline & & Wheezing $(p<0.001)$ \\
\hline & & Breathlessness $(p<0.001)$ \\
\hline & & Presence of exacerbations $(p<0.001)$ \\
\hline & & Intensity of exacerbations $(\mathrm{p}<0.001)$ \\
\hline \multirow[t]{18}{*}{ PACD [18] } & PACQLQ [50] activity change over 21 days & Asthma status, stable versus unstable ${ }^{+}$adjusted for age and clinic \\
\hline & Symptom/activity scale $r=-0.27$ (SS) & Symptom/activity scale $(p=0.0001)$ \\
\hline & DWAS $r=0.19$ (SS) & Mean per cent DWAS $37 \%$ in stable group versus $11 \%$ in unstable group $(p=0.0001)$ \\
\hline & PACQLQ emotional change over 21 days & \\
\hline & Symptom/activity scale $r=-0.34$ (SS) & \\
\hline & DWAS $r=0.32$ (SS) & \\
\hline & Change in physician severity rating & \\
\hline & Symptom/activity scale $r=-0.43$ (SS) & \\
\hline & DWAS $r=-0.37$ (SS) & \\
\hline & Change in $\beta$-agonist treatments & \\
\hline & Symptom/activity scale $r=0.65$ (SS) & \\
\hline & DWAS not applicable & \\
\hline & Change in physician global assessment & \\
\hline & Symptom/activity scale $r=0.39$ (SS) & \\
\hline & DWAS $r=-0.28$ (SS) & \\
\hline & Change in caregiver global assessment & \\
\hline & Symptom/activity scale $r=0.47$ (SS) & \\
\hline & DWAS $r=-0.28$ (SS) & \\
\hline \multirow[t]{9}{*}{ РАCT [44] } & ITG Child Asthma Short Form (QOL measure) [53] & Not reported \\
\hline & Frequency of flares domain $r=0.61(p<0.01)$ & \\
\hline & Symptoms at best domain $r=0.77(p<0.01)$ & \\
\hline & Specialist clinician assessment & \\
\hline & Frequency of flares domain $r=0.54(p<0.01)$ & \\
\hline & Symptoms at best domain $r=0.59(p<0.01)$ & \\
\hline & FEV $1 \%$ pred & \\
\hline & Frequency of flares domain $r=-0.12$ (Ns) & \\
\hline & Symptoms at best domain $r=-0.29(p<0.01)$ & \\
\hline \multirow{9}{*}{$\begin{array}{l}\text { PedsQL } 3.0 \text { SF22 } \\
\text { Asthma Module } \\
\text { [46] }\end{array}$} & Impact on Family Scale [54] & Asthma severity level, post hoc pairwise comparisons for both scales: \\
\hline & Asthma symptoms $r=-0.14(p<0.01)$ & Mild intermittent versus mild persistent $(p<0.05)$ \\
\hline & Treatment problems $r=-0.19(p<0.01)$ & Mild persistent versus moderate-severe persistent $(p<0.05)$ \\
\hline & School and sports days missed by child & Mild intermittent versus moderate-severe persistent $(p<0.05)$ \\
\hline & Asthma symptoms $r=-0.33(p<0.01)$ & \\
\hline & Treatment problems $r=-0.34(p<0.01)$ & \\
\hline & Work days missed by parent & \\
\hline & Asthma symptoms $r=-0.28(p<0.01)$ & \\
\hline & Treatment problems $r=-0.26(p<0.01)$ & \\
\hline \multirow{4}{*}{$\begin{array}{l}\text { PedsQL Asthma } \\
\text { Symptoms Scale } \\
\text { [45] }\end{array}$} & PedsQL 4.0 Generic Core Scales [55] & Asthma severity level (mild, moderate, severe): \\
\hline & Total score $r=0.49(p<0.001)$ & Mild versus severe $(p<0.001)$ \\
\hline & & Mild versus moderate $(p<0.001)$ \\
\hline & & NS difference between moderate and severe \\
\hline \multirow[t]{4}{*}{ TRACK [47] } & Not reported (factor analysis conducted) & Physician rating of control $(p<0.001)[47,50]$ \\
\hline & & Physician recommendation for change in therapy $(p<0.001)[47,50]$ \\
\hline & & Symptom frequency $(p<0.001)[47]$ \\
\hline & & Caregiver-reported frequency of asthma attacks in past 3 months at baseline $(p<0.001)$ [50] \\
\hline
\end{tabular}

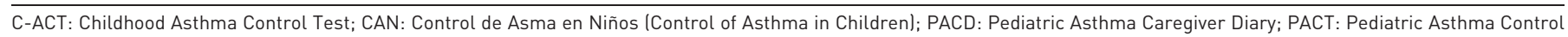

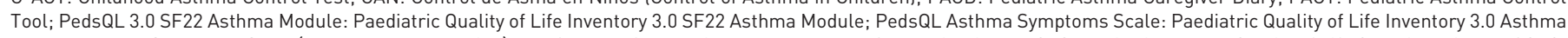

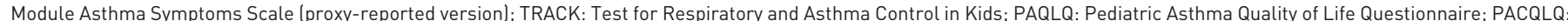

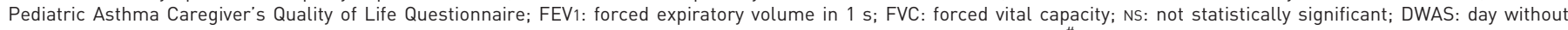

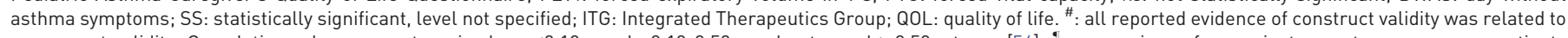

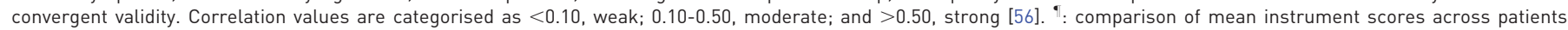

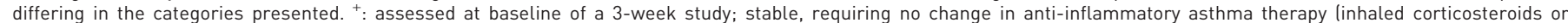

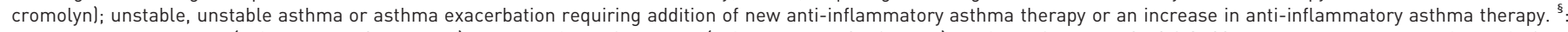

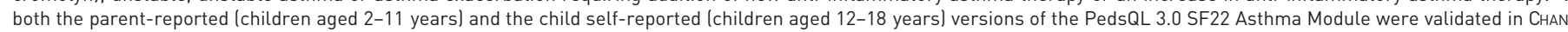

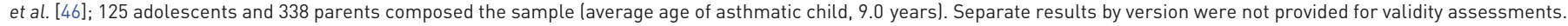

change in percentage of days of $\beta$-agonist use; and reduction in overnight asthma symptoms among patients reporting overnight symptoms on two or more nights per week at baseline [48]. The PACD also demonstrated responsiveness to change in a prospective validation study [18]. The diary questions and symptom/activity scale detected significant differences between the two asthma severity groups $(\mathrm{p}<0.01)$ for change from baseline over 3 weeks, with the exception of the item on caregiver loss of work. The PACD differentiated between children with stable and unstable asthma at baseline, despite low symptom scores 
(between 0 and 1) and small sample size. Finally, the PACD questions were responsive to adding or increasing inhaled anti-inflammatory therapy among children who were unstable and symptomatic at baseline compared with a group who were stable and relatively asymptomatic at baseline and who remained stable throughout the study [18].

The PedsQL Asthma Symptoms Scale was included as a secondary outcome measure in an RCT of a behavioural intervention [10]. The trial examined the effect of problem-solving skill training for caregivers of 252 children aged 3 to 14 years with persistent asthma. The participants were predominantly lower socioeconomic status Spanish-speaking Hispanic families. However, the PedsQL Asthma Symptoms Scale identified no statistically significant differences among groups receiving standard care waitlist (control), home-visiting asthma education or care coordination and combined intervention of asthma education or problem-solving skill training either at baseline, after intervention, or at 6-months of follow-up [10]. The validation of the PxRO PedsQL Asthma Symptoms Scale was conducted in this trial, and the scale exhibited responsiveness by identifying statistically significant within-subject change from baseline to 3 months for those classified as clinically improved by asthma symptom frequency score $(\mathrm{p}<0.001)$ [45], and it also differentiated between children who improved clinically and those who remained stable from baseline to 3 months of follow-up based on caregiver reports of asthma symptom frequency $(\mathrm{p}<0.0001)$.

The CAN showed responsiveness to clinical change in a 12-week validation study in Spain [42]. In this prospective observational study, 215 caregivers of patients aged 2 to 8 years with moderate or severe asthma completed the CAN at baseline and weeks two and 12 . At week 12, there was a statistically significant mean reduction in CAN scores (indicating improved control) of 7.5 to 8 points for each symptom in patients whose symptoms had improved, total scores range from 0 ("best control") to 36 ("worst control"). Mean scores increased (indicating worsening of asthma) in patients whose symptoms had worsened at week 12, with mean increases of 4.4 to 5.1 points $(\mathrm{p}<0.001)$ [42].

The responsiveness of the C-ACT was assessed in a longitudinal validation study among 338 children aged 4 to 11 years with asthma and their caregivers at two visits, 4 to 6 weeks apart [49]. Asthma control was rated by asthma specialists at each visit. Significant differences in C-ACT scores were observed among groups of patients whose level of control improved, did not change, or worsened $(\mathrm{p}<0.001)$.

A longitudinal validation study of the TRACK was conducted with 438 caregivers of children younger than 5 years with symptoms consistent with asthma within the previous year [50]. The study demonstrated the TRACK's responsiveness to change in proxy-reported respiratory control status. Caregivers completed the TRACK at two clinic visits separated by 4 to 6 weeks. Physicians completed a US guideline-based (National Asthma Education and Prevention Program Expert Panel Report 3) respiratory control survey at both visits and were asked whether the visit resulted in a change in therapy. Mean changes in TRACK scores from the initial to follow-up visits differed in the expected direction with subsets of children whose clinical status improved, remained unchanged, or worsened based on physician and caregiver assessments $(\mathrm{p}<0.001)$.

Table 5 provides a summary of the psychometric properties achieved, as reported in the literature, for each of the seven PxRO instruments of interest.

\section{Discussion}

This literature review focused on identifying and evaluating PxRO instruments assessing asthma symptoms, asthma control and asthma-specific HRQOL that would be suitable for use in clinical trials of children with asthma aged 6 years or younger. Based on findings from previous research [8, 25-27] and regulatory agency guidelines $[24,29,30]$, we excluded instruments that were not validated for use by caregivers of young children, that focused on caregiver or family functioning, or that asked caregivers to report extensively on subjective concepts, such as the child's worry or fear. Researchers or clinicians who wish to evaluate older children (aged 7-11 years) or to examine more general or subjective quality of life domains may want to consider the instruments recommended by the 2010 National Institutes of Health and Agency for Healthcare Research and Quality Asthma Outcomes workshop [59].

The potential usefulness of the seven instruments meeting the criteria of this review varies; several instruments offer important strengths and some have potential weaknesses in assessing treatment benefit in the context of a paediatric asthma clinical trial. Six of the instruments were developed specifically for proxy reporting in paediatric asthma, and one instrument was a combination of proxy-reported and child-reported items.

Among the instruments evaluated, the PACD meets most of the requirements of an instrument to be used in a clinical trial. It was developed appropriately with measurement properties that generally meet or exceed recognised standards, and it allows caregivers to report on observable symptoms or behaviours related to asthma. Responsiveness in an RCT was one of the key considerations of the review and the PACD was the only instrument demonstrating this characteristic in an RCT of drug therapy. Cognitive interviews with 
TABLE 5 Summary of psychometric properties reported in the literature for proxy-reported outcome instruments of interest

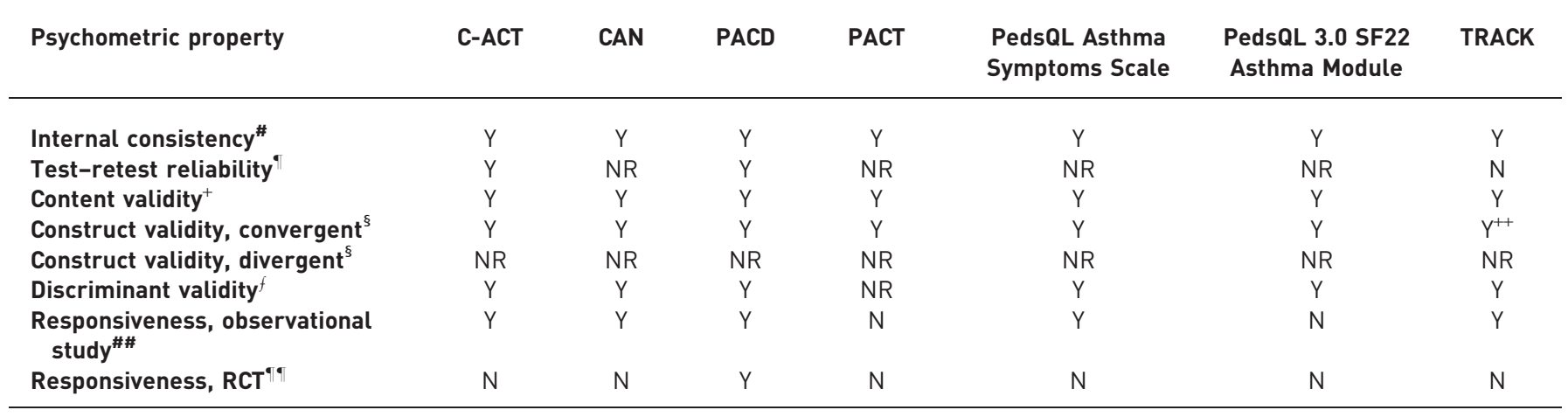

C-ACT: Childhood Asthma Control Test; CAN: Control de Asma en Niños (Control of Asthma in Children); PACD: Pediatric Asthma Caregiver Diary; PACT: Pediatric Asthma Control Tool; PedsQL Asthma Symptoms Scale: Pediatric Quality of Life Inventory 3.0 Asthma Module Asthma Symptoms Scale (proxy-reported version); PedsQL 3.0 SF22 Asthma Module: Pediatric Quality of Life Inventory 3.0 SF22 Asthma Module; TRACK: Test for Respiratory and Asthma Control in Kids; RCT: randomised controlled trial; Y: instrument achieved or exceeded the established psychometric standard or the standard set by the authors of this review; NR: not reported; N: instrument did not meet the established psychometric standard or the standard set by the authors of this review. "\#: range for acceptable Cronbach's $\alpha>0.70$ but $\leqslant 0.95$ [35]; ": threshold for acceptable test-retest reliability intraclass correlation coefficient $\geqslant 0.70[51]_{;}{ }^{+}$: target population (caregivers of children with asthma) provided input in the development of the instrument in one or more of the following areas: generation of item concept and wording, evaluation of completeness of item coverage, or assessment of item clarity and readability; ${ }^{\S}$ : at least one Pearson's correlation coefficient ( $r$ ) value was categorised as moderate (0.10-0.50) or strong (>0.50) [56]; ${ }^{f}$ : discriminant validity demonstrated by statistically significant $(p<0.05)$ difference in at least one comparison of patient subgroups with differing clinical features; \#\#: responsiveness demonstrated by statistically significant ( $p<0.05)$ proxy-reported outcome (PxRO) results in at least one longitudinal observational study; ${ }^{\text {"T}}$ : responsiveness demonstrated by statistically significant ( $\left.p<0.05\right)$ PxRO results in at least one randomised controlled trial; ${ }^{++}$: convergent validity supported by factor analysis.

paediatric asthma caregivers were performed to confirm the items, although the PACD's development does not appear to have included caregiver input into generation of the items (concept elicitation) [18].

The PACD also has the advantage of being a daily diary with a brief recall period of $12 \mathrm{~h}$, which is consistent with recall period expectations outlined in the FDA PRO guidance [24] and which allows characterisation of the daily variation in symptoms, which tend to be highly variable in asthma [60].

The TRACK has appropriate measurement properties and may be an option for assessing asthma control in some paediatric asthma clinical trials, especially multiyear studies. The TRACK includes input from caregiver and physician interviews and caregiver focus groups in the questionnaire development phase, supporting good content validity. Moreover, validation of the TRACK was conducted with children younger than 5 years, so no "lower limit" on age exists for use of this measure, and responsiveness to clinical changes occurring over 4 to 6 weeks was demonstrated in a longitudinal validation study [50]. The TRACK also assesses the risk of exacerbations as recommended in the National Asthma Education and Prevention Program Expert Panel Report 3 [61]. However, the TRACK was developed primarily for use in clinical practice, rather than clinical trial settings. Limitations of the TRACK in the clinical trial setting are that the recall periods are lengthy and vary substantially across the five items (4-week recall for symptoms $(n=3)$, 3-month recall for rescue medication use $(n=1)$, and 12-month recall for oral corticosteroid use $(\mathrm{n}=1))$, resulting in potential difficulties with interpreting the total score and demonstrating treatmentrelated change over time periods of less than 12 months. The TRACK also has not been used in any published clinical trials so its responsiveness in an interventional study setting is currently unknown.

The PedsQL Asthma Symptoms Scale appears to be another potential alternative: versions were validated for children aged 2 years and older; the initial development was based on focus groups, cognitive testing, and pretesting $[8,62]$; psychometric properties were adequate and generally met current standards; and the instrument has been used in an RCT in paediatric asthma patients. However, the trial using the PedsQL Asthma Symptoms Scale examined a behavioural intervention (problem-solving skill training) rather than a drug treatment and the measure did not find statistically significant between-group differences [10]. This study also reported no significant between-group differences for proxy-reported daytime symptoms, emergency department visits, or unscheduled office visits, so the problem-solving training appears to have had limited impact on asthma symptom frequency and severity. Limitations of the PedsQL Asthma Symptoms Scale related to use in a paediatric asthma clinical trial are the relatively long recall period of 4 weeks and inclusion of an item requiring a subjective assessment of the child's fear during an asthma attack, which may be difficult for a parent or caregiver to accurately ascertain for their very young child. 
The C-ACT, CAN, PACT and PedsQL 3.0 SF22 Asthma Module are less promising for assessing PxROs in clinical trials. Each instrument has been developed with a relatively lengthy recall period (either 4 weeks or 3 months). In its guidance document on PRO development for industry, the FDA states that "PRO instruments that call for patients to rely on memory, especially if they must recall over a long period of time, compare their current state with an earlier period, or average their response over a period of time, are likely to undermine content validity. For these reasons, items with short recall periods or items that ask patients to describe their current or recent state are usually preferable" [24].

Additionally, the C-ACT has been validated for children aged 4 to 11 years and may not be appropriate for use with children younger than 4 years. The CAN has been validated only in Spanish, to date, and contains items related to emergency department visits and hospitalisations for asthma that may not be useful in a clinical trial setting. The PedsQL 3.0 SF22 Asthma Module Treatment Problems scale contains items related to anxiety or the extent of bother caused by asthma that require subjective assessment.

Although it is recognised that "proxy assessments are not sufficiently able to take into account the subjective nature of quality-of-life measurement" [28] and may be subject to undue influence of the burden of the child's health condition on the caregiver [63], PxROs are reasonable options for assessing observable symptoms and effects of disease, particularly with young children. Based on this review, three existing PxRO instruments would be potential options for use as end-points in clinical trials assessing young children with asthma. The evidence identified suggests that the PACD possesses the strongest measurement properties of the three and it has demonstrated responsiveness in an RCT of a drug therapy in this population.

Additional qualitative work could be conducted to supplement the content validity or to evaluate a shorter recall period for instruments with weaknesses in these properties. The lack of formal assessment of responsiveness to change in an interventional study was an important shortcoming among most of the instruments included in this review and should be a priority for future research. Clinical trials using instruments concurrently should be conducted so that relative responsiveness and convergent validity can be evaluated. This review also has shown variety in the content of the seven PxRO asthma-specific instruments. Potential users should consider the content of instruments in relation to the patient population and research questions. Additional research is also needed related to the optimal age for child self-report of asthma symptoms, asthma control and asthma-specific HRQOL.

\section{Acknowledgements}

The authors wish to acknowledge the assistance of psychometricians Theresa M. Coles and Lauren Nelson of RTI Health Solutions.

\section{References}

1 Masoli M, Fabian D, Holt S, et al. The global burden of asthma: executive summary of the GINA Dissemination Committee report. Allergy 2004; 59: 469-478.

2 World Health Organization Europe. Prevalence of Asthma and Allergies in Children. Fact Sheet No. 3.1. May 2007. www.euro.who.int/_data/assets/pdf_file/0012/96996/3.1.pdf Date last accessed: June 4, 2012.

3 Bloom B, Cohen RA, Freeman G. Summary Health Statistics for U.S. Children: National Health Interview Survey, 2010. National Center for Health Statistics. Vital Health Stat 10 (250) 2011. www.cdc.gov/nchs/data/series/sr_10/ sr10_250.pdf Date last accessed: June 4, 2012.

4 Asthma Burden. In: Loddenkemper R, Gibson GJ, Sibille Y, eds. European Lung White Book. Lausanne, European Respiratory Society, 2003; pp. 16-25.

5 Asthma and Allergy Foundation of America (AAFA), Asthma Facts and Figures. www.aafa.org/display. $\mathrm{cfm} ? \mathrm{id}=8 \& \mathrm{sub}=42 \#$ ftnref2 Date last accessed: October 6, 2011.

6 Hall MJ, DeFrances CJ, Williams SN, et al. National hospital discharge survey: 2007 summary. In: National Health Statistics Reports No 29. Hyattsville, National Center for Health Statistics, 2010. www.cdc.gov/nchs/data/nhsr/ nhsr029.pdf Date last accessed: October 12, 2011.

7 Akinbami LJ, Moorman JE, Garbe PL, et al. Status of childhood asthma in the United States, 1980-2007. Pediatrics 2009; 123: Suppl. 3, S13I-S145.

8 Varni JW, Burwinkle TM, Rapoff MA, et al. The PedsQL in pediatric asthma: reliability and validity of the Pediatric Quality of Life Inventory Generic Core Scales and Asthma Module. J Behav Med 2004; 27: 297-318.

9 Varni JW, Limbers CA, Burwinkle TM. Impaired health-related quality of life in children and adolescents with chronic conditions: a comparative analysis of 10 disease clusters and 33 disease categories/severities utilizing the PedsQL 4.0 Generic Core Scales. Health Qual Life Outcomes 2007; 5: 43.

10 Seid M, Varni JW, Gidwani P, et al. Problem-solving skills training for vulnerable families of children with persistent asthma: report of a randomized trial on health-related quality of life outcomes. J Pediatr Psychol 2010; 35: $1133-1143$.

11 Global Initiative for Asthma (GINA). Global Strategy for the Diagnosis and Management of Asthma in Children 5 Years and Younger, 2009. www.ginasthma.org/ Date last accessed: October 12, 2011.

12 Landgraf JM, Abetz LN. Measuring health outcomes in pediatric populations: issues in psychometrics and application. In: Spilker B, ed. Quality of Life and Pharmacoeconomics in Clinical Trials. 2nd Edn. Philadelphia, Lippincott-Raven Publishers, 1996; pp. 793-802. 
13 Juniper E. Paediatric Asthma Quality of Life Questionnaires (PAQLQ, PAQLQ(S), MiniPAQLQ and PACQLQ): Background, Administration and Analysis, 2006. www.qoltech.co.uk/paediatric\%20_aqlq_package.html Date last accessed: September 19, 2012.

14 Annett RD, Bender BG, Lapidus J, et al. Predicting children's quality of life in an asthma clinical trial: what do children's reports tell us? J Pediatr 2001; 139: 854-861.

15 Campo JV, Comer DM, Jansen-McWilliams L, et al. Recurrent pain, emotional distress, and health service use in childhood. J. Pediatr 2002; 141: 76-83.

16 Janicke DM, Finney JW, Riley AW. Children's health care use: a prospective investigation of factors related to careseeking. Med Care 2001; 39: 990-1001.

17 Varni JW, Setoguchi Y. Screening for behavioral and emotional problems in children and adolescents with congenital or acquired limb deficiencies. Am J Dis Child 1992; 146: 103-107.

18 Santanello NC, Demuro-Mercon C, Davies G, et al. Validation of a pediatric asthma caregiver diary. J Allergy Clin Immunol 2000; 106: 861-866.

19 Carlsen KH, Carlsen KCL. Tidal breathing analysis and response to salbutamol in awake young children with and without asthma. Eur Respir J 1994; 7: 2154-2159.

20 van der Ent CK, Brackel HJL, van der Laag J, et al. Tidal breathing analysis as a measure of airway obstruction in children three years of age and older. Am J Respir Crit Care Med 1996; 153: 1253-1258.

21 Klug B, Bisgaard H. Measurement of lung function in awake 2-4-year old asthmatic children during methacholine challenge and acute asthma: a comparison of the impulse oscillation technique, the interrupter technique, and transcutaneous measurement of oxygen versus whole-body plethysmography. Pediatr Pulmonol 1996; 21: 290-300.

22 Ducharme FM, Davis GM. Measurement of respiratory resistance in the emergency department: feasibility in young children with acute asthma. Chest 1997; 111: 1519-1525.

23 Ducharme FM, Davis GM. Respiratory resistance in the emergency department: a reproducible and responsive measure of asthma severity. Chest 1998; 113: 1566-1572.

24 US Department of Health and Human Services. Guidance for Industry. Patient-reported Outcome Measures: Use in Medical Product Development to Support Labeling C12dlaims. December 2009 www.fda.gov/downloads/Drugs/ GuidanceComplianceRegulatoryInformation/Guidances/UCM193282.pdf Date last accessed: June 13, 2011.

25 Cremeens J, Eiser C, Blades M. Factors influencing agreement between child self-report and parent proxy-reports on the Pediatric Quality of Life Inventory 4.0 (PedsQL) generic core scales. Health Qual Life Outcomes 2006; 4: 58.

26 Morrow AM, Hayen A, Quine S, et al. A comparison of doctors', parents' and children's reports of health states and health-related quality of life in children with chronic conditions. Child Care Health Dev 2012; 38: 186-195.

27 Annett RD, Bender BG, DuHamel TR, et al. Factors influencing parent reports on quality of life for children with asthma. J Asthma 2003; 40: 577-587.

28 Rutishauser C, Sawyer SM, Bowes G. Quality-of-life assessment in children and adolescents with asthma. Eur Respir J 1998; 12: 486-494.

29 European Medicines Agency. Reflection Paper on the Regulatory Guidance for the use of Health Related Quality of Life (HRQL) Measures in the Evaluation of Medicinal Products. 2005. www.ispor.org/workpaper/EMEA-HRQLGuidance.pdf Date last accessed: November 3, 2011.

30 European Medicines Agency. Note for Guidance on the Clinical Investigation of Medicinal Products in the Treatment of Asthma, 2002. www.ema.europa.eu/docs/en_GB/document_library/Scientific_guideline/2009/09/ WC500003555.pdf Date last accessed: September 19, 2012.

31 Juniper EF, Gruffydd-Jones K, Ward S, et al. Asthma Control Questionnaire in children: validation, measurement properties, interpretation. Eur Respir J 2010; 36: 1410-1416.

32 Critical Path Institute (C-Path). Creating Consensus Science, New Tools and Tactics for Next-Gen Drug Development Conference. Session III: Patient-Reported Outcome Instruments as Drug Development Tools. 2011. www.c-path.org/Events/creating_consensus_science/session3_patient_reported_outcomes_instruments_as_tools. pdf Date last accessed: September 4, 2012.

33 US National Institutes of Health. ClinicalTrials.gov. www.clinicaltrials.gov/ Date last accessed: May 15, 2011.

34 MAPI Research Trust. Patient-Reported Outcome and Quality of Life Instruments Database (PROQOLID). www. proqolid.org/ Date last accessed: May 11, 2011.

35 Cronbach L. Coefficient $\alpha$ and the internal structure of tests. Psychometrika 1951; 16: 294-334.

36 Lomas J, Pickard L, Mohide A. Patient versus clinician item generation for quality-of-life measures. The case of language-disabled adults. Med Care 1987; 25: 764-769.

37 Guyatt GH, Cook DJ. Health status, quality of life, and the individual. JAMA 1994; 272: 630-631.

38 Fitzpatrick R, Davey C, Buxton MJ, et al. Evaluating patient-based outcome measures for use in clinical trials. Health Technol Assess 1998; 2: 1-74.

39 Kirshner B, Guyatt GH. A methodological framework for assessing health indices. J Chronic Dis 1985; 38: 27-36.

40 Kirshner B. Methodological standards for assessing therapeutic equivalence. J Clin Epidemiol 1991; 44: 839-849.

41 Liu AH, Zeiger R, Sorkness C, et al. Development and cross-sectional validation of the Childhood Asthma Control Test. J Allergy Clin Immunol 2007; 119: 817-825.

42 Pérez-Yarza EG, Badía X, Badiola C, et al. Development and validation of a questionnaire to assess asthma control in pediatrics. Pediatr Pulmonol 2009; 44: 54-63.

43 Santanello NC. Pediatric asthma assessment: validation of 2 symptom diaries. J Allergy Clin Immunol 2001; 107: S465-S472.

44 Zorc JJ, Pawlowski NA, Allen JL, et al. Development and validation of an instrument to measure asthma symptom control in children. J Asthma 2006; 43: 753-758.

45 Seid M, Limbers CA, Driscoll KA, et al. Reliability, validity, and responsiveness of the pediatric quality of life inventory (PedsQL) generic core scales and asthma symptoms scale in vulnerable children with asthma. J Asthma 2010; 47: 170-177.

46 Chan KS, Mangione-Smith R, Burwinkle TM, et al. The PedsQL: reliability and validity of the short-form generic core scales and asthma module. Med Care 2005; 43: 256-265.

47 Murphy KR, Zeiger RS, Kosinski M, et al. Test for respiratory and asthma control in kids (TRACK): a caregivercompleted questionnaire for preschool-aged children. J Allergy Clin Immunol 2009; 123: 833-839. 
Knorr B, Franchi LM, Bisgaard H, et al. Montelukast, a leukotriene receptor antagonist, for the treatment of persistent asthma in children aged 2 to 5 years. Pediatrics 2001; 108: E48.

49 Sorkness CA, Liu AH, Blaiss M, et al. Longitudinal validation of the Childhood Asthma Control Test. Am J Respir Crit Care Med 2007; 175: A782.

50 Chipps B, Zeiger RS, Murphy K, et al. Longitudinal validation of the Test for Respiratory and Asthma Control in Kids in pediatric practices. Pediatrics 2011; 127: e737-e747.

51 Streiner DL, Norman GR. Health Measurement Scales: a Practical Guide to their Development and Use. 2nd Edn. New York, Oxford University Press, 1995.

52 Juniper EF, Guyatt GH, Feeny DH, et al. Measuring quality of life in children with asthma. Qual Life Res 1996; 5: 35-46.

53 Bukstein DA, McGrath MM, Buchner DA, et al. Evaluation of a short form for measuring health-related quality of life among pediatric asthma patients. J Allergy Clin Immunol 2000; 105: 245-251.

54 Stein RE, Riessman CK. The development of an impact-on-family scale: preliminary findings. Med Care 1980; 18: 465-472.

55 Varni JW, Seid M, Kurtin PS. PedsQL 4.0TM: reliability and validity of the Pediatric Quality of Life Inventory Version 4.0 Generic Core Scales in healthy and patient populations. Med Care 2001; 39: 800-812.

56 Cohen J. Statistical Power Analysis for the Behavioral Sciences. 2nd Edn. Hillsdale, Lawrence Erlbaum Associates, 1988.

57 Juniper EF, O’Byrne PM, Guyatt GH, et al. Development and validation of a questionnaire to measure asthma control. Eur Respir J 1999; 14: 902-907.

58 Deyo RA, Diehr P, Patrick DL. Reproducibility and responsiveness of health status measures. Statistics and strategies for evaluation. Controlled Clin Trials 1991; 12: Suppl. 4, S142-S158.

59 Busse WW, Morgan WJ, Taggart V, et al. Asthma outcomes workshop: overview. J Allergy Clin Immunol 2012; 129: Suppl. 3, S1-S8.

60 Reddel HK, Taylor DR, Bateman ED, et al. An official American Thoracic Society/European Respiratory Society statement: asthma control and exacerbations. Standardizing endpoints for clinical asthma trials and clinical practice. Am J Respir Crit Care Med 2009; 180: 59-99.

61 National Heart Lung and Blood Institute, National Asthma Education and Prevention Program. Expert Panel Report 3: Guidelines for the Diagnosis and Management of Asthma. Bethesda, National Institutes of Health/ National Heart, Lung, and Blood Institute, 2007. Available from: www.nhlbi.nih.gov/guidelines/asthma/asthgdln. htm.

62 Varni JW, Burwinkle TM, Seid M. The PedsQL as a pediatric patient-reported outcome: reliability and validity of the PedsQL Measurement Model in 25,000 children. Expert Rev Pharmacoecon Outcomes Res 2005; 5: 705-719.

63 Rothman ML, Hendrick SC, Blucroft KA, et al. The validity of proxy-generated scores as measures of patient health status. Med Care 1991; 29: 115-124. 